\title{
Glycemic Control in Pregnant Diabetic Woman: Comparison between Conventional Insulin and Analogs
}

Olfa Berriche*, Haifa Sfar, Faten Mahjoub, Emna Fenira, Rym Ben othmen, Imen Ksira, Amel Gamoudi, Chiraz Amrouche and Henda Jamoussi National Institute of Nutrition, BAB SAÂDOUN TUNIS Tunisie, Tunisia

"Corresponding author: Olfa Berriche, National Institute of Nutrition, BAB SAÂDOUN TUNIS Tunisie, Tunisia, Tel: +216410861; E-mail: olfaberriche1@gmail.com Received date: May 13, 2017; Accepted date: May 25, 2017; Published date: May 30, 2017

Copyright: ( 2017 Berriche O, et al. This is an open-access article distributed under the terms of the Creative Commons Attribution License, which permits unrestricted use, distribution, and reproduction in any medium, provided the original author and source are credited.

\begin{abstract}
Background: Pregnancy in diabetic women is at high-risk of maternal and fetal complications. Insulin which remains the main treatment during pregnancy is not devoid of adverse effects mainly hypoglycemia and weight gain. The objective of our study was to evaluate the efficiency and safety of insulin analogs compared to conventional insulin in a group of pregnant women with diabetes.

Methods: A prospective longitudinal study comparing two groups of diabetic pregnant women (including type 1(T1DM) and type 2 diabetes mellitus (T2DM)): group 1 (G1) made of 43 patients on conventional insulin and group 2 (G2) made of 30 patients on analogues. Patients were enrolled at a gestational age before 12 weeks and were followed until childbirth.

Results: At baseline, age, types of diabetes, duration of diabetes and average $\mathrm{HbA} 1 \mathrm{c}$ at the first trimester were similar between treatment groups. Upon study of glycemic profiles, in the third trimester, the mean group 2 fasting plasma glucose (FPG) was lower compared to group 1(G1: $1.19 \pm 0.32 \mathrm{~g} / \mathrm{l}$ vs. G2: $1.05 \pm 0.26 \mathrm{~g} / \mathrm{l} ; \mathrm{p}=0.06$ ). Mean evening pre-prandial glucose was although significantly higher in group 2 in the $1^{\text {st }}$ and $2^{\text {nd }}$ trimesters became comparable to that in group 1 in the 3rd quarter, indeed a significant improvement with insulin analogues was shown $(p=0.042)$. The rest of the glycemic profile was comparable in both groups as well as HbA1c levels throughout pregnancy (HbA1c T3: G1: $6.7 \pm 1.2 \%$ vs. G2: $7.18 \pm 1.1 \%$; $=0.16)$. The episodes of nocturnal and severe hypoglycemia were similar in both groups. Weight gain was lower in G2 than in G1 but the difference was not significant (G1: $10.27 \pm 5.46 \mathrm{~kg}$ versus $\mathrm{G} 2: 7.69 \pm 5.34 \mathrm{~kg} ; \mathrm{p}=0.082$ ).
\end{abstract}

Conclusion: Our study showed that insulin analogs were not inferior to conventional insulin to achieve glycemic control during pregnancy.

Keywords: Insulin; Diabetes; Pregnancy; Analogs; Hypoglycemia

\section{Introduction}

Diabetes during pregnancy is accompanied by increasing needs for maternal insulin and ongoing biological changes that cause maternal insulin requirements to reach higher and lower extremes throughout the day than in non-pregnant patients. As maternal hyperglycemia increases the risk of fetal and maternal morbidity, it is essential for the mother to maintain normoglycemia during pregnancy [1]. Given the potential benefits of insulin analogs compared with more conventional human insulin, many women of child-bearing age are now receiving these analogs and would prefer to continue using them during pregnancy. Consequently, it is very important to study the safety and efficacy of basal insulin analogs in pregnant women with diabetes. The primary aim of this study was to compare glycemic control as measured by $\mathrm{A} 1 \mathrm{C}$ each trimester and 6-point plasma glucose profiles monthly in pregnant women with type 1 or 2 diabetes treated with either insulin analogs or conventional insulin. This article presents data on glycemic control, maternal hypoglycemia, and maternal safety.

\section{Patients and Methods}

This prospective, longitudinal, randomized study was conducted between December 2014 and February 2016 in the National Institute of Nutrition of Tunis. Eligible subjects were all pregnant women with a viable singleton or twin gestation at gestational age $<12$ weeks, with either preexisting T2DM or T1DM, in need of medical therapy, who received care at our institution. All patients were treated with basalbolus insulin therapy (detemir or NPH, aspart or human insulin at the 3 main meals). This population consisted of 73 subjects enrolled assigned in early pregnancy who accepted to participate in the study (30 to insulin analogs and 43 to conventional insulin). The follow-up was carried out by monthly hospitalizations, in collaboration with the gynecologists of other hospitals in Tunis. Additional visits according to local practice and individual needs were also given. All basal insulin doses were titrated according to fasting or predinner capillary plasma glucose (PG) values. Al bolus insulin doses were titrated according to pre- and postprandial PG values. All insulin doses (both bolus and basal) were adjusted, in accordance with recommendations of the American Diabetes Association in 2015 [2], according to a preprandial PG target of $60-99 \mathrm{mg} / \mathrm{dL}(3.3-5.4 \mathrm{mmol} / \mathrm{L})$ and a $2-\mathrm{h}$ postprandial glucose target of 100-129 mg/dL (5.4-7.1 mmol/L). Insulin dose and weight gain during the pregnancy period were calculated. 
Maternal safety during pregnancy reported here included major and nocturnal hypoglycemia, deterioration of retinopathy, adverse events (AEs). Major hypoglycemia was defined as an episode in which the subject was unable to treat herself; minor hypoglycemia was defined as an episode in which the subject was able to treat herself and had a PG reading of $\leq 3.9 \mathrm{mmol} / \mathrm{l}$ [2]. Episodes were recorded by the subjects in their trial diaries. Subjects had deterioration of retinopathy if fundoscopy progressed from "normal" at the first pregnancy visit to" abnormal" at follow-up, or from "abnormal, not clinically significant" to "abnormal, clinically significant" at follow-up. Fundoscopy/fundus photography was performed according to local practice, dated, and recorded in the trial report form, and was sourcedata verifiable.

The analysis of the data and the choice of the statistical tests were carried out thanks to the collaboration of the department of preventive medicine of the faculty of medicine of Tunis and using the software SPSS version 19.0.

The descriptive study involved all patients recruited at the beginning of the study. Absolute frequencies and relative frequencies (percentages) were calculated for the qualitative variables. We calculated averages, medians and standard deviations and determined the extreme values for the quantitative variables. The comparative study of the two groups according to the evolution during the pregnancy only concerned the patients who had a follow-up until the $3^{\text {rd }}$ trimester and whose information concerning the course of the delivery and the health of the newborn were collected. Comparisons of 2 means on independent series were performed using the Student $t$ test for independent series and in the case of low numbers by the nonparametric Mann and Whitney test. Comparisons of 2 matchedrun averages were performed using the Student $t$-test for matched series, and in the case of numbers $<30$ by Wilcoxon's nonparametric matched series test. Comparisons of several $(>2)$ averages on independent series were carried out using the Snedecor analysis of parametric variance analysis (ANOVA to a factor) and verified in case of low numbers by the Kruskall-Wallis $\mathrm{H}$ test Analysis of nonparametric variance. In the case of a significant difference, comparisons 2-2 were made using the Bonferroni method. The comparisons of percentages on independent series were made by the Pearson chi-square test and in case of significance to the chi-square test and non-validity of this test and comparison of 2 percentages, by the exact test Bilateral Fisher. The comparisons of 2 percentages on matched series were carried out by the Mac Nemar test, and in the event of non-validity of this test, by the use of the properties of the binomial law. The links between two quantitative variables were studied by the Pearson correlation coefficient and in the case of nonvalidity by the correlation coefficient of the ranks of Spearman. In all cases, the threshold of statistical significance $\mathrm{p}$ was set at 0.05 .

\section{Results}

The main subject demographics at baseline are shown in Table 1 and were similar between treatment groups. Twenty-three patients on insulin analogs and thirty-seven patients on conventional insulin were left for analysis; All results are reported from the per protocol analysis (Figure 1).

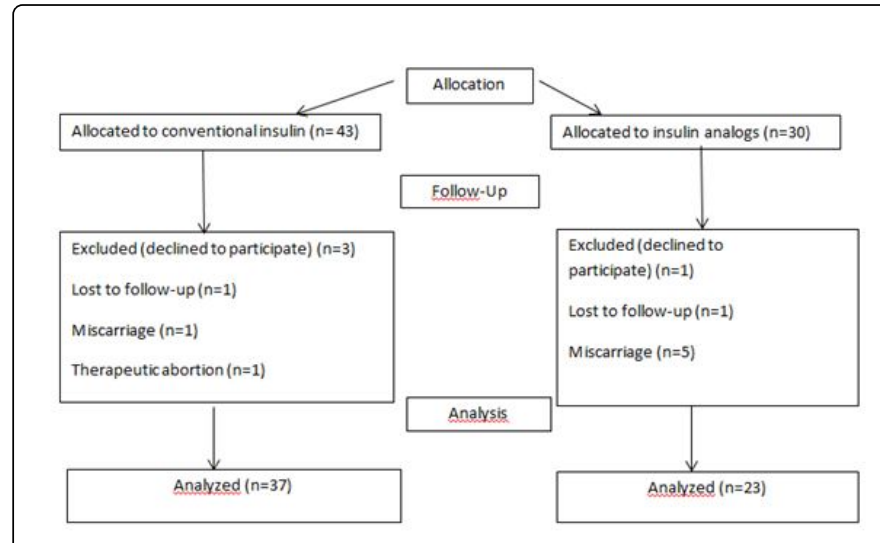

Figure 1: Trial flowchart per protocol analysis.

\begin{tabular}{|c|c|c|c|}
\hline & Group 1 & Group 2 & $\mathbf{p}$ \\
\hline Age(years) & $33.10 \pm 5.39$ & $31.86 \pm 6.39$ & 0.36 \\
\hline Prepregnancy body mass index $\left(\mathrm{kg} / \mathrm{m}^{2}\right)$ & $28.95 \pm 5.44$ & $26.89 \pm 7.62$ & 0.19 \\
\hline Passive smoking (\%) & 45 & 32 & 0.30 \\
\hline Number of previous pregnancies $1-3(\%)$ & 67 & 79 & 0.47 \\
\hline $0(\%)$ & 52 & 41 & 0.14 \\
\hline T1DM (\%) & 45 & 55 & 0.40 \\
\hline Duration of diabetes (years) & $7.02 \pm 6.74$ & $7.50 \pm 6.53$ & 0.82 \\
\hline Retinopathy T0 (\%) & 7 & 15 & 0.38 \\
\hline Nephropathy T0 (\%) & 11 & 9 & 0.51 \\
\hline PrepregnancyHbA1c (\%) & $7.83 \pm 1.73$ & $7.62 \pm 2.12$ & 0.75 \\
\hline Pre-conception counseling (\%) & 18 & 11 & 0.40 \\
\hline
\end{tabular}

Table 1: Subject demographics.

For the primary outcome, Estimated mean FPG for those on conventional insulin and those on insulin analogs were comparable to the first and second trimesters of pregnancy. In the third trimester, the mean of FPG in group 2 was lower compared to group 1 (G1: $1.19 \pm$ $0.32 \mathrm{~g} / \mathrm{l}$ vs. $\mathrm{G} 2: 1.05 \pm 0.26 \mathrm{~g} / \mathrm{l} ; \mathrm{p}=0.06$ ) (Figure 2). The mean FPG variations of the two groups were similar $(\Delta \mathrm{FPG}(\mathrm{T} 2-\mathrm{T} 1)$ : G1: $0.17 \pm$ $0.55 \mathrm{~g} / \mathrm{l} ; \mathrm{G} 2: 0.19 \pm 0.7 \mathrm{~g} / \mathrm{l} ; \mathrm{p}=0.88 ; \Delta \mathrm{FPG}(\mathrm{T} 3-\mathrm{T} 2) ; \mathrm{G} 1: 0.19 \pm 0.49 \mathrm{~g} / \mathrm{l}$; G2: $0.36 \pm 0.57 \mathrm{~g} / \mathrm{l} ; \mathrm{p}=0.24)$. Mean evening pre-prandial glucose although significantly higher in group 2 in the 1 st(G1: $1.29 \pm 0.66 \mathrm{~g} / \mathrm{l}$ vs. G2: $1.87 \pm 0.7 \mathrm{~g} / \mathrm{l} ; \mathrm{p}=0.001)$ and $2^{\text {nd }}$ trimesters (G1: $1.25 \pm 0.36 \mathrm{~g} / \mathrm{l}$ vs. G2:1.57 $\pm 0.62 \mathrm{~g} / \mathrm{l}, \mathrm{p}=0.025)$ became comparable to that in group 1 in the 3rd quarter(G1: $1.27 \pm 0.42 \mathrm{~g} / \mathrm{l}$ vs. $\mathrm{G} 2: 1.35 \pm 0.52 \mathrm{~g} / \mathrm{l} ; \mathrm{p}=0.55)$ indeed a significant improvement with insulin analogues was shown (Figure 3).The mean postprandial blood glucose (PPBG)in the evening in the $2^{\text {nd }}$ trimester was significantly higher in group $2(\mathrm{p}=0.007)$, while the other PPBG at the different periods of pregnancy were comparable in the two groups (Table 2). There was no statistically significant difference between the mean HbAlc of the two groups throughout the study (Figure 4); The highest incidence of patients achieving the HbAlc goal of less than $6 \%$ was observed in the 2nd trimester for the two groups (Figure 5). The $\Delta \mathrm{HbAlc}$ (HbAlcT3- 
Citation: Berriche O, Sfar H, Mahjoub F, Fenira E, Ben othmen R, et al. (2017) Glycemic Control in Pregnant Diabetic Woman: Comparison between Conventional Insulin and Analogs. J Diabeteas Metab 8: 743. doi:10.4172/2155-6156.1000743

Page 3 of 6

HbAlcT1) was $-1.41 \pm 1.57 \%$ (min: $4.80 \%$; max: $+1.5 \%$ ) in group 1 and $-0.79 \pm 1.26 \%$ (Min: $-4.10 \%$; $\max :+1.3 \%)$ in group $2(\mathrm{p}=0.13)$.

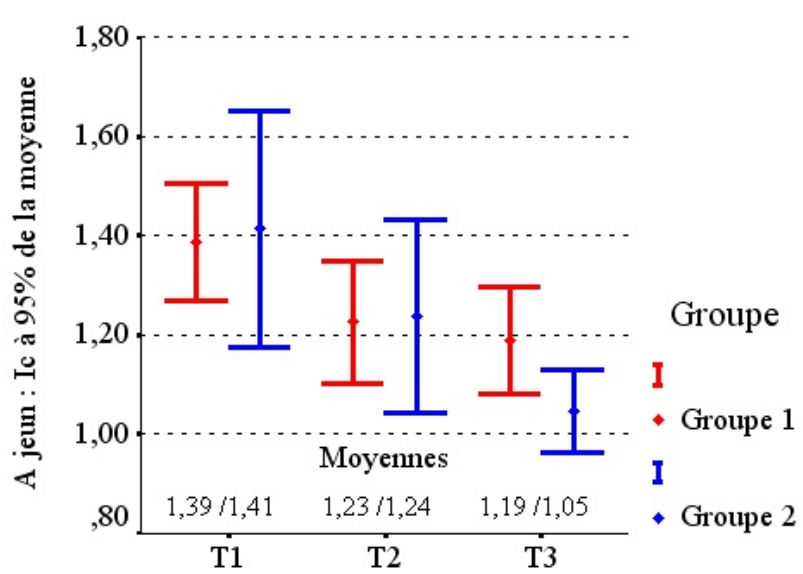

\section{Trimestre}

Figure 2: Mean FPG of each group on T1, T2 and T3.

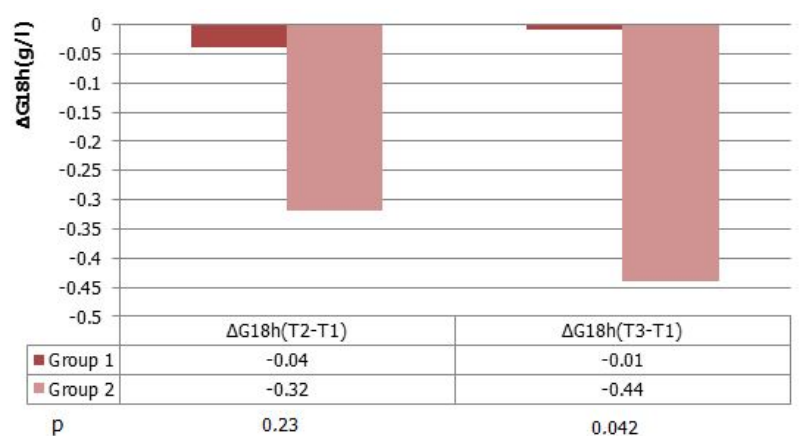

Figure 3: Mean changing of evening pre-prandial glucose of each group on $\mathrm{T} 2$ and $\mathrm{T} 3$.

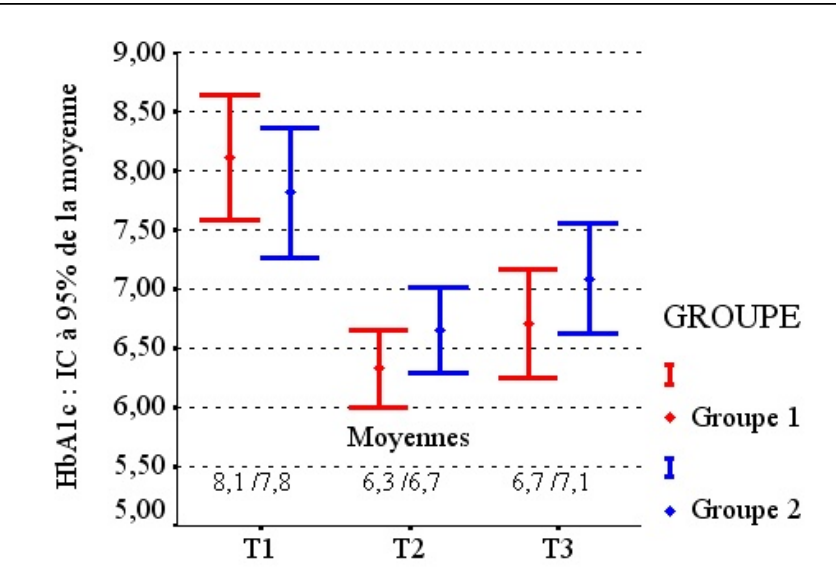

Trimestre

Figure 4: Mean HbA1c of each group on T1, T2 and T3.

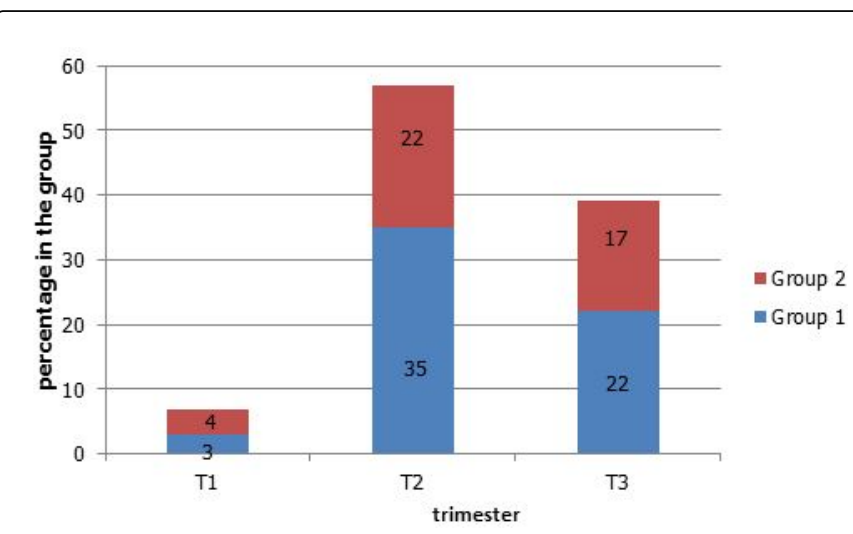

Figure 5: Percentage of patients in the two groups who achieved the glycemic target of $\mathrm{HbAlc}<6 \%$ at $\mathrm{T} 1, \mathrm{~T} 2$ and $\mathrm{T} 3$.

\begin{tabular}{|c|c|c|c|c|c|c|c|c|c|}
\hline & \multicolumn{3}{|l|}{ 1st trimester } & \multicolumn{3}{|l|}{ 2nd trimester } & \multicolumn{3}{|l|}{ 3rd trimester } \\
\hline & G1 & G2 & $\mathbf{P}$ & G1 & G2 & $\mathbf{P}$ & G1 & G2 & $\mathbf{P}$ \\
\hline $\begin{array}{l}\text { Morning } \\
\text { PPBG }\end{array}$ & $1.86 \pm 0.54 \mathrm{~g} / \mathrm{l}$ & $1.89 \pm 0.71 \mathrm{~g} / \mathrm{l}$ & 0.86 & $1.68 \pm 0.43 \mathrm{~g} / \mathrm{l}$ & $1.75 \pm 0.53 \mathrm{~g} / \mathrm{l}$ & 0.58 & $1.72 \pm 0.36 \mathrm{~g} / \mathrm{l}$ & $1.59 \pm 0.63 \mathrm{~g} / \mathrm{l}$ & 0.33 \\
\hline $\begin{array}{l}\text { Midday } \\
\text { PPBG }\end{array}$ & $1.72 \pm 0.54 \mathrm{~g} / \mathrm{l}$ & $1.73 \pm 0.67 \mathrm{~g} / \mathrm{l}$ & 0.84 & $1.48 \pm 0.45 \mathrm{~g} / \mathrm{l}$ & $1.68 \pm 0.55 \mathrm{~g} / \mathrm{l}$ & 0.65 & $1.56 \pm 0.39 \mathrm{~g} / \mathrm{l}$ & $1.77 \pm 0.78 \mathrm{~g} / \mathrm{l}$ & 0.16 \\
\hline $\begin{array}{l}\text { Evening } \\
\text { PPBG }\end{array}$ & $1.53 \pm 0.62 \mathrm{~g} / \mathrm{l}$ & $1.68 \pm 0.65 \mathrm{~g} / \mathrm{l}$ & 0.34 & $1.43 \pm 0.42 \mathrm{~g} / \mathrm{l}$ & $1.77 \pm 0.59 \mathrm{~g} / \mathrm{l}$ & 0.013 & $1.61 \pm 0.43 \mathrm{~g} / \mathrm{l}$ & $1.80 \pm 0.77 \mathrm{~g} / \mathrm{l}$ & 0.2 \\
\hline
\end{tabular}

Table 2: Mean PPBG in both groups at T1, T2 and T3.

The need for insulin increased throughout pregnancy in both groups and was higher in group 2 with a more marked difference in the third trimester $(\mathrm{G} 1: 0.84 \pm 0.29 \mathrm{UI} / \mathrm{kg} / \mathrm{d} ; \mathrm{G} 2: 1.01 \pm 0.34 \mathrm{U} / \mathrm{kg} / \mathrm{d}$; $\mathrm{p}=0.05)$.
Nocturnal hypoglycaemic episodes were less frequent in Group 2 than Group 1 in the 1 st and $3^{\text {rd }}$ trimester with a non-significant difference. On the other hand, the percentage of patients with at least 
one episode of nocturnal hypoglycemia was significantly higher in Group 2 than in group 1 in the $2^{\text {nd }}$ trimester $(\mathrm{p}=0.03$ ) (Figure 6).

Means of episodes of severe hypoglycemia per month were comparable in two groups $2(\mathrm{~T} 1: \mathrm{p}=0.28, \mathrm{~T} 2: \mathrm{p}=0.31, \mathrm{~T} 3: \mathrm{p}=0.19)$ (Figure 7).

Two patients, one in group 1 and the other in group 2, had an episode of ketosis in the first and second trimester due to a urinary tract infection. No patient presented ketoacidosis.

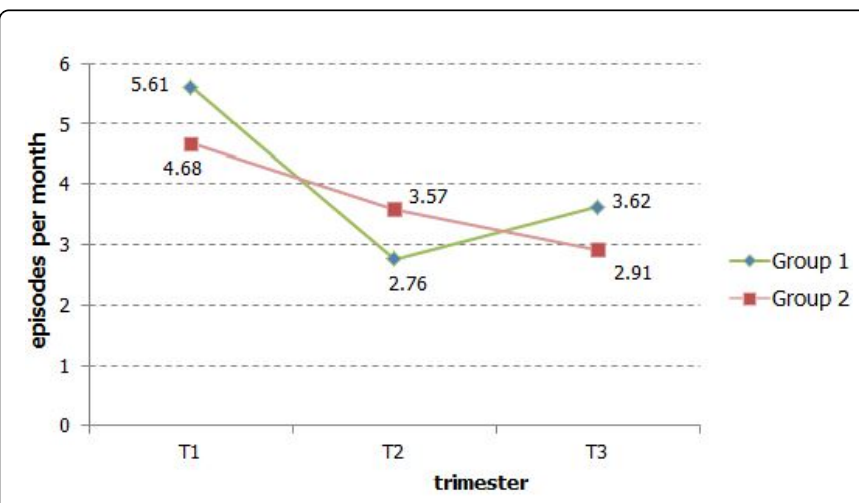

Figure 6: Mean episodes of nocturnal hypoglycemia per month in the $\mathrm{T} 1, \mathrm{~T} 2$ and $\mathrm{T} 3$.

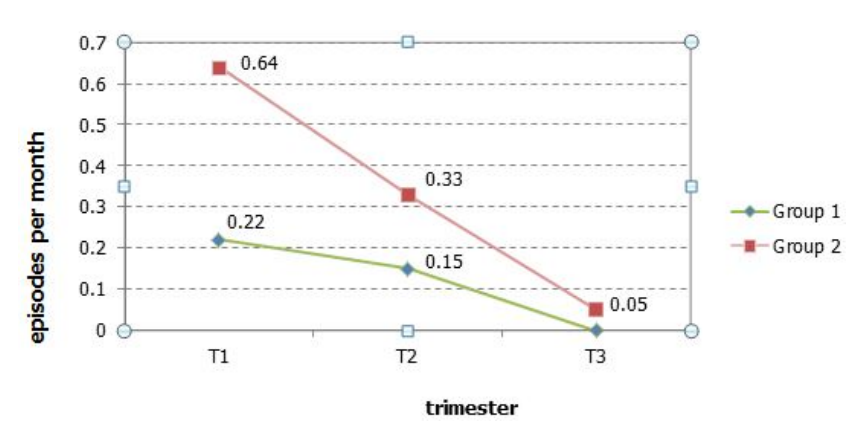

Figure 7: Averages of episodes of severe hypoglycemia per month in the study population at $\mathrm{T} 1, \mathrm{~T} 2$ and $\mathrm{T} 3$.

In group 2, three patients aggravated their diabetic retinopathy but no case of progression of non-proliferative retinopathy to proliferative was observed in either group; the difference between the two groups was not significant $(\mathrm{p}=0.38)$. Renal function remained stable throughout pregnancy for both groups. Patients with positive albuminuria in early pregnancy did not develop macroalbuminuria. Mean weight gain was lower in group 2 than in group 1 in the three trimesters, more notable in the third trimester (G1: $10.27 \mathrm{~kg}$ vs $\mathrm{G} 2$ : $7.69 \mathrm{~kg} ; \mathrm{p}=0.08)$.

\section{Discussion}

In our study, insulin detemir was able to equilibrate fasting blood glucose as well as NPH insulin and was even better in the third trimester. Results of our study were similar to those found in the Herrera study [3], which examined pregnant women with type 2 diabetes or gestational diabetes, average fasting glucose during pregnancy was $1.01 \pm 0.9 \mathrm{~g} / \mathrm{l}$ and $0.99 \pm 0.88 \mathrm{~g} / \mathrm{l}$ respectively in the detemir arm and the NPH insulin arm. A large randomized controlled study [4]comparing insulin detemir versus NPH insulin, both associated with insulin asparte included a total of 310 pregnant women with diabetes type 1 recruited on preconception or already pregnant with a gestational age less than 12 gestational weeks (GWs). This study showed that fasting glucose levels at 24 GWs and 36 GWs in the detemir group were significantly lower than those in the NPH group. This difference was found in the patients recruited before pregnancy but was not noted in the patients recruited in the first weeks of pregnancy, which is the case of our patients confirming our results.

In our series, apart from the mean postprandial blood glucose in the evening during the 2 nd trimester, the different postprandial glucose levels on insulin aspart were comparable to those under ordinary insulin.

Several studies [5-8] in diabetics aside from pregnancy found better control of postprandial glucose with insulin aspart, which has encouraged its prescription in pregnant women. Indeed, lower postprandial blood glucose levels during pregnancy were correlated with decreased perinatal complications [9].

A large international randomized study, conducted by Mathiesen [10] in 18 countries, was conducted in 322 pregnant women with type 1 diabetes, including 157 on insulin aspartand 165 on ordinary insulin, but all with insulin NPH. This study showed superiority of insulin aspart compared to fast human insulin during the $1^{\text {st }}$ and $3^{\text {rd }}$ trimester in the balance of postprandial blood glucose especially in the morning.

As regards $\mathrm{HbAlc}$, The data from the literature are comparable to our results. Indeed, the various studies $[4,11,12]$ comparing insulin detemir with insulin NPH during pregnancy did not show superiority or inferiority of the slow analog versus NPH on the control of HbAlc. Studies concerning aspart also found $\mathrm{HbAlc}$ comparable to that found with ordinary insulin throughout pregnancy $[10,13,14]$. Mac Manus and Rayan estimated insulin requirements to decrease by 10 to $20 \%$ by the twelfth week of pregnancy and then to increase from the eighteenth to the thirty-sixth week [15].

The Mathiesen study [4,11] carried out in 2012 showed that the mean total insulin doses at $14 \mathrm{GWs}$ were $0.73 \mathrm{U} / \mathrm{kg} / \mathrm{d}$ in the detemir group and $0.74 \mathrm{U} / \mathrm{kg} / \mathrm{d}$ in the group NPH and at $36 \mathrm{GWs}$ were 1.17 $\mathrm{U} / \mathrm{kg} /$ day in the detemir group and $1.05 \mathrm{U} / \mathrm{kg} /$ day in the NPH group $(\mathrm{p}=\mathrm{NS})$. Intensification of doses has mainly concerned fast insulin.

This result is supported by Mathiesen's first study [10] which also showed that doses of insulin boli were lower in the aspart group than in the regular insulin group $[10,14]$. At the end of the 3rd trimester the rapid insulin doses were very high confirming the interest of fast analogues that allow a less aggressive titration of insulin for a better glycemic balance with a lower risk of hypoglycaemia.

We didn't study fast and slow insulin doses separately so the higher doses of insulin in group 2 could be explained by the fact that for the same hypoglycaemic power detemir needs 2 to 4 times higher doses than those of NPH $[16,17]$. Insulin detemir actually has less affinity than insulin NPH for the insulin receptor [18].

Episodes of nocturnal hypoglycemia were less in the insulin analog group but with no significant difference; On the other hand, severe hypoglycaemia was described more in this group but also without significant difference. The latter result could be explained on the one hand by a slightly higher frequency of type 1 diabetics in group 2 and on the other hand the indication of insulin analogues could have been 
Page 5 of 6

posed hypoglycaemia in some patients and thus constituting a selection bias.

Insulin analogues offer the opportunity to mimic the physiological secretion of insulin thus allowing more flexibility and freedom to patients and a lower risk of hypoglycaemia [19]. Insulin detemir disappears more slowly from the subcutaneous tissue than NPH and has a more "flat" pharmacodynamics than of NPH (no peak action at usual doses). A study [20] comparing the variability of resorption of insulin detemir with that of insulin NPH concluded that the resorption variability was lower for insulin detemir. As for insulin aspart [21], its delay of action, of the order of 5 to 15 minutes, is twice as short as that of the conventional rapid with a peak of action around 30 to 90 minutes.

In vitro, the affinity of insulin aspart for the insulin receptor is comparable to that of conventional insulin. he main advantage of the rapid analog is that the pre-prandial injection can be done just before the meal, 15 minutes before (more if the blood glucose is high) or even at the end of the meal if the amount of carbohydrate in the meal is not known, without deterioration of HbAlc [22]. In case of hypoglycaemia at meal time, the injection will be delayed in the middle or at the end of the meal.

Among pregnant women, in 2003, Pettitt et al. [23] were the first to study the clinical efficacy of insulin asparte versus human insulin in 15 patients with gestational diabetes. They reported a higher, but not significant, frequency of hypoglycaemia in the insulin aspart group but no episodes of severe hypoglycemia were observed. In contrary, the Heller study [12] showed a lower risk of severe diurnal and nocturnal hypoglycaemia in the insulin asparte arm but without significant difference.

This result is similar to that found in the Mathiesen study $[10,14]$. The latter [14] found a risk of hypoglycemia all confused comparable between the two groups. Studies that have been interested $[3,4,11,15,24]$ in insulin detemir in pregnant women, have not shown, likewise, a significant difference in the frequency of hypoglycemia compared to human insulin. However, Vellanki et al. [24,17] showed a percentage of patients with at least one episode of hypoglycemia comparable between the two groups (detemir group: 26\%, human insulin group: $36 \%$; $\mathrm{p}=0.34$ ) while the number of episodes of symptomatic and biological hypoglycaemia per week was significantly higher in the insulin NPH group than in the insulin detemir group.

\section{Conclusion}

Our work is the first in Tunisia comparing insulin analogs to human insulin in pregnant women. We showed the non-inferiority of insulin analogs in glycemic control during pregnancy. We did not find a significant decrease in hypoglycaemia under analogs. The development of insulin analogs has provided a greater choice for patients with diabetes than in the past, and it appears that their use in pregnancy is increasing. This may reflect a change in the perception of the safety of insulin analog use in pregnancy, supported by FDA endorsement. Finally, the therapeutic choice, especially insulin therapy, should be the discussed between the patient and the practitioner, taking into consideration the patient's glycemic profile, lifestyle and social security.

\section{Limits of This Study}

Our work has certain limits; the small size of the sample. Thus, there was lost patients and we didn't evaluate the quality of life of our patients and their satisfaction with the treatment in both groups.

\section{References}

1. Tennant PWG, Glinianaia SV, Bilous RW, Rankin J, Bell R (2014) Preexisting diabetes, maternal glycatedhaemoglobin, and the risks of fetal and infant death: a population-based study. Diabetologia 57: 285294.

2. American Diabetes Association. Standards of medical care in diabetes 2015. In: Diabetes Care 2015.

3. Herrera KM, Rosenn BM, Foroutan J, Bimson BE, Al Ibraheemi Z, et al. (2015) Randomized controlled trial of insulin detemir versus NPH for the treatment of pregnant women with diabetes. Am J Obstet Gynecol 213: 426; e1-7.

4. Mathiesen ER, Hod M, Ivanisevic M, Garcia SD, Brøndsted L, et al (2015) Maternal efficacy and safety outcomes in a randomized, controlled trial comparing insulin detemir with NPH insulin in 310 pregnant women with type 1 diabetes. Diabetes Care 35: 2012-2017.

5. Owens DR, Zinman B, Bolli GB (2001) Insulins today and beyond. Lancet Lond Engl 358:739746.

6. Tamás GY, Marre M, Astorga R, Dedov I, Jacobsen J, et al. (2001) Glycaemic control in type 1 diabetic patients using optimised insulin aspart or human insulin in a randomised multinational study. Diabetes Res Clin Pract 54: 105-114.

7. Home PD, Lindholm A, Riis A (2000) Insulin aspart vs. human insulin in the management of long-term blood glucose control in type 1 diabetes mellitus: a randomized controlled trial. Diabet Med 17: 762-770.

8. Raskin P, Guthrie RA, Leiter L, Riis A, Jovanovic L (2000) Use of insulin aspart, a fast-acting insulin analog, as the mealtime insulin in the management of patients with type 1 diabetes. Diabetes Care 23: 583-588.

9. de Veciana M, Major CA, Morgan MA, Asrat T, Toohey JS, et al. (1995) Postprandial versus Preprandial Blood Glucose Monitoring in Women with Gestational Diabetes Mellitus Requiring Insulin Therapy. N Engl J Med 333: 12371241

10. Mathiesen ER, Kinsley B, Amiel SA, Heller S, McCance D, et al. (2007) Maternal Glycemic Control and Hypoglycemia in Type 1 Diabetic Pregnancy A randomized trial of insulin aspart versus human insulin in 322 pregnant women. Diabetes Care 30: 771-776.

11. Mello G, Biagioni S, Ottanelli S, Nardini C, Tredici Z, et al. (2015) Continuous subcutaneous insulin infusion (CSII) versus multiple daily injections (MDI) of rapid-acting insulin analogues and detemir in type 1 diabetic (T1D) pregnant women. J Matern Fetal Neonatal Med 28: 276280.

12. Shenoy VV, Cook SJ, Parry AF, McIntyre HD (2012) Audit of insulin detemir in pregnancy: a retrospective case series. Diabet Med J Br Diabet Assoc 29: 958959.

13. Heller S, Damm P, Mersebach H, Skjøth TV, Kaaja R, et al. (2010) Hypoglycemia in Type 1 Diabetic Pregnancy Role of preconception insulin aspart treatment in a randomized study. Diabetes Care 33: 473-477.

14. Cianni GD, Volpe L, Ghio A, Lencioni C, Cuccuru I, et al. (2007) Maternal Metabolic Control and Perinatal Outcome in Women With Gestational Diabetes Mellitus Treated With Lispro or Aspart Insulin Comparison with regular insulin. Diabetes Care 30: e11.

15. McManus RM, Ryan EA (1992) Insulin Requirements in InsulinDependent and Insulin-Requiring GDM Women During Final Month of Pregnancy. Diabetes Care 15:1323-1327.

16. Hermansen K, Madsbad S, Perrild H, Kristensen A, Axelsen M (2001) Comparison of the soluble basal insulin analog insulin detemir with NPH insulin: a randomized open crossover trial in type 1 diabetic subjects on basal-bolus therapy. Diabetes Care 24: 296301. 
Citation: Berriche O, Sfar H, Mahjoub F, Fenira E, Ben othmen R, et al. (2017) Glycemic Control in Pregnant Diabetic Woman: Comparison between Conventional Insulin and Analogs. J Diabeteas Metab 8: 743. doi:10.4172/2155-6156.1000743

Page 6 of 6

17. Vague P, Selam JL, Skeie S, De Leeuw I, Elte JWF, et al. (2003) Insulin detemir is associated with more predictable glycemic control and reduced risk of hypoglycemia than NPH insulin in patients with type 1 diabetes on a basal-bolus regimen with premeal insulin aspart. Diabetes Care 26:590-596.

18. Kurtzhals P, Schäffer L, Sørensen A, Kristensen C, Jonassen I, et al. (2000) Correlations of receptor binding and metabolic and mitogenic potencies of insulin analogs designed for clinical use. Diabetes 49: 999-1005.

19. Evans M, Schumm-Draeger PM, Vora J, King AB (2011) A review of modern insulin analogue pharmacokinetic and pharmacodynamic profiles in type 2 diabetes: improvements and limitations. Diabetes Obes Metab 13: 677-684.

20. Heise T, Nosek L, Rønn BB, Endahl L, Heinemann L, et al. (2004) Lower within-subject variability of insulin detemir in comparison to NPH insulin and insulin glargine in people with type 1 diabetes. Diabetes 53: 1614-1620.

21. Sola A, Larger E, M’Bemba J, Elgrably F, Slama G (2006) Les nouvelles insulines $\bigotimes$ : intérêts et inconvénients. Réanimation. 15:454-460.

22. Setter SM, Corbett CF, Campbell RK, White JR (2000) Insulin aspart: a new rapid-acting insulin analog. Ann Pharmacother 34: 1423-1431.

23. Pettitt DJ, Ospina P, Kolaczynski JW, Jovanovic L (2003) Comparison of an insulin analog, insulin aspart, and regular human insulin with no insulin in gestational diabetes mellitus. Diabetes Care 26: 183-186.

24. Vellanki P, Umpierrez G (2016) Detemir is non-inferior to NPH insulin in women with pregestational type 2 diabetes and gestational diabetes mellitus. Evid Based Med 21: 104-105. 